\title{
Enhancing Pharmacovigilance from the US Experience: Current Practices and Future Opportunities
}

\author{
Veronique F. Kugener ${ }^{1}$ - Eric S. Freedland ${ }^{1} \cdot$ Kenneth I. Maynard ${ }^{1} \cdot$ Omar Aimer $^{2}$ (D) . Peggy S. Webster ${ }^{3}$. \\ Maribel Salas ${ }^{4}$ (D) Maxine Gossell-Williams ${ }^{5}$ (1)
}

Accepted: 29 April 2021 / Published online: 15 May 2021

(C) The Author(s), under exclusive licence to Springer Nature Switzerland AG 2021

\begin{abstract}
This review is intended to present perspectives from the US experience in enhancing pharmacovigilance on current practices and future opportunities. Best practices concepts could be applied worldwide through the presentation of how three pillars of pharmacovigilance: (1) medical and scientific excellence, (2) operational and compliance excellence, and (3) knowledge sharing and experts development in the field could serve as a framework for the establishment of an efficient and successful global pharmacovigilance system.
\end{abstract}

\section{Key Points}

Pharmacovigilance comprises a set of multiple and complex regulated activities and has to adapt to the rapid advancement of new therapies.

A three-pillar model could serve as a framework for the establishment of an efficient and successful global pharmacovigilance system.

Medical and scientific excellence, operational and compliance excellence, and knowledge sharing and experts development in the field are the tenets of the proposed three-pillar model.

Veronique F. Kugener

Veronique.Kugener@Takeda.com

Eric S. Freedland

Eric.Freedland@Takeda.com

Kenneth I. Maynard

kenneth.maynard@takeda.com

Omar Aimer

omar.aimer@innovigilance.com

Peggy S. Webster

Peggy.s.webster@gsk.com

Maribel Salas

msalas@dsi.com

Maxine Gossell-Williams

Maxine.gossell@uwimona.edu.jm

\section{Introduction}

Pharmacovigilance (PV) is an important function with the mission of primarily ensuring the safety of patients with the use of pharmaceuticals, including biologics, such as vaccines, plasma-derived therapies and/or medical devices, which are in clinical development or in the post-marketing setting. Pharmacovigilance functions work collaboratively with highly skilled clinical experts from various disciplines (e.g., medicine, pharmacy, pharmaceutical sciences, biostatistics, informatics, epidemiology) and other cross functions worldwide.

Pharmacovigilance has to constantly adapt to a rapidly evolving regulatory landscape and to the dizzying pace of advancement of new therapies and technologies. These demands require ongoing awareness and training of not only

1 Global Patient Safety Evaluation, Research \& Development, Takeda Pharmaceuticals International Co., 300

Massachusetts Avenue, Cambridge, MA 02139, USA

2 Brunel Canada, Laval, QC, Canada

3 GlaxoSmithKline, Philadelphia, PA, USA

4 Daiichi Sankyo, Inc. and CCEB/CPeRT, Perelman School of Medicine, University of Pennsylvania, Philadelphia, PA, USA

5 Section of Pharmacology and Pharmacy, Faculty of Medical Sciences Teaching and Research Complex, University of The West Indies, Kingston, Jamaica 
current PV experts, but also behoove the recruitment and training of experts for the future.

Most PV practices are guided by local and regional healthcare systems and regulations, as well as international regulations. These share the objectives of continuously and timely collecting, assessing, monitoring, and reporting safety data for compounds and products either in clinical development or in the post-marketing setting.

The PV community maintains a collaborative and harmonizing spirit to share best practices worldwide. This review is intended to present current PV practices and future opportunities from the US experience. These best practices concepts could be applied worldwide through the presentation of how three pillars of PV: (1) medical and scientific excellence; (2) operational and compliance excellence; and (3) knowledge sharing and experts development in the field could serve as a framework for the establishment of an efficient and successful global PV system (Fig. 1).

\section{PILLAR I: Medical and Scientific Excellence}

The convergence of medical science, data science, and technology has accelerated the pace of transformative scientific discoveries that are helping medical practice rewrite the script for detecting, preventing, and treating diseases in our society. Precision medicine is now possible with the advent of groundbreaking therapies that harness the human genome or immune system, and we have witnessed an inflection point in our ability to treat and potentially cure diseases that were previously thought to be outside the reach of medicine. Advances in translational medicine have fostered the discovery of new biomarkers that allow for enhanced prediction and monitoring of target organ toxicities, and novel uses of existing datasets can enrich safety evidence generation. The following examples further illustrate how constant advances in medicine and science challenge PV to continue to uphold an efficient and successful framework.

\subsection{Advancement in Gene Therapy Medicines}

Gene therapy products are now being studied in many diseases and conditions, including genetic disorders, autoimmune diseases, heart disease, cancer, diabetes mellitus, and human immunodeficiency virus/acquired immunodeficiency syndrome [1]. Recognizing the traditional phase I-IV clinical trial process is unsuitable for the development of these emerging therapies has led to not only regulators developing guidelines specifically focused on expediting the approval process, but also raises concerns about the reliability of benefit-risk assessment processes [2-4]. These evolving challenges, which apply to safety assessment, have prompted the active updating of regulatory guidelines for human gene therapy products [5]. With the advancement of potential new therapies giving hope to millions of patients, all parties involved in the healthcare system must continue to develop a proactive approach to ensure the continuous benefit-risk assessment for innovative medicines and contribute to carefully plan and monitor drug development and the post-marketing phase of these new therapies. Gene therapy products are designed to provide benefit through a long-acting or permanent mechanism of action, and the resulting longterm exposure may place subjects of investigational studies at increased risk for delayed adverse effects requiring additional PV activities. Patients may therefore need to be followed up for 15 years for genome editing products [6]. There are also options of enrolling patients from phase III randomized controlled trials into observational open-label
Fig. 1 Proposed three-pillar model of an optimized, fully integrated, global pharmacovigilance system

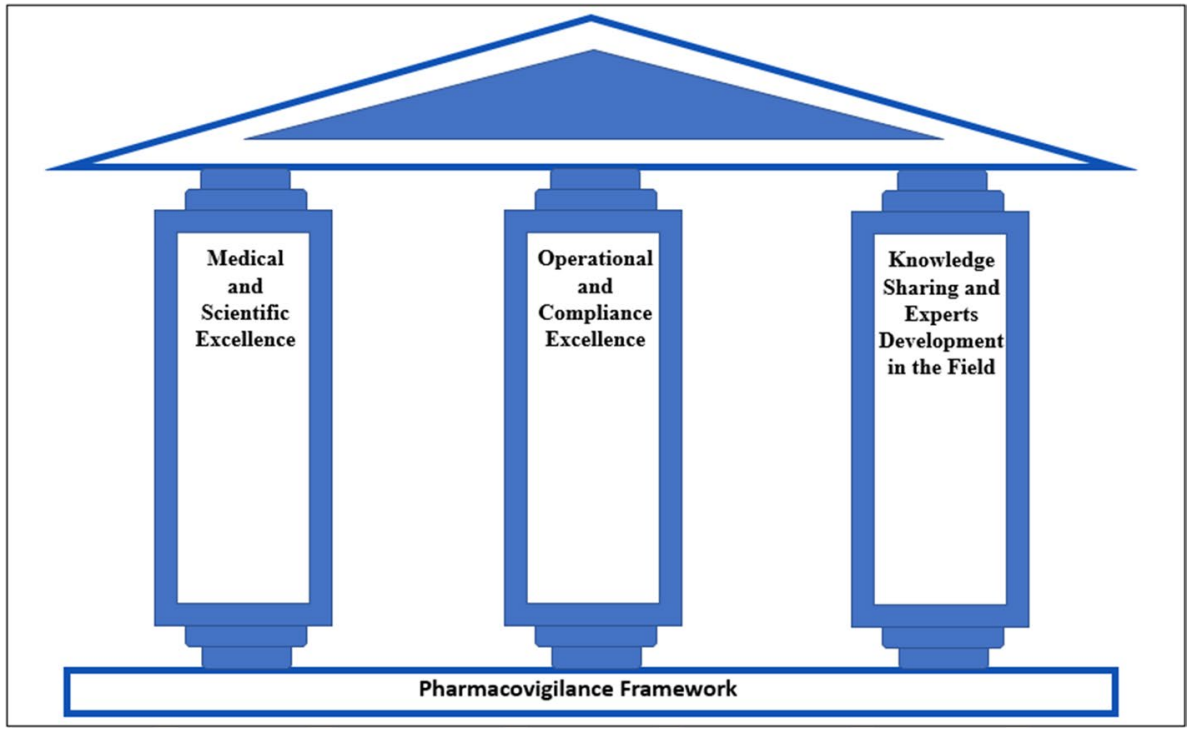


extension studies or to create a global registry of treated patients [7, 8]; such studies are currently active for US Food and Drug Administration (FDA)-approved gene therapy [6].

\subsubsection{Chimeric Antigen Receptor T-Cell Therapy}

In August 2017, the FDA approved the first gene therapy, tisagenlecleucel, followed by the approval of axicabtagene ciloleucel in October 2017. Both are chimeric antigen receptor (CAR) T-cell therapies for lymphoblastic leukemia [3, 4, 9]. A third CAR T-cell therapy, brexucabtagene autoleucel, was approved for the treatment of mantle cell lymphoma in July 2020 [10]. Chimeric antigen receptor T-cell therapy is a customized treatment that uses the patient's own T lymphocytes, which are then genetically modified ex vivo with a gene that encodes a chimeric antigen receptor to direct the patient's $\mathrm{T}$ cells against the malignancy. The T cells are expanded in a production facility prior to being infused back into the patient [11]. All three approved CAR T-cell therapies target the CD19 protein on B cells and have shown promise in achieving remission with some patients needing no further therapy for at least 3 years $[9,12]$. However, the overall durability of these responses is yet to be determined. Furthermore, major safety issues have been observed across all indications. For example, cytokine release syndrome is reported in most treated patients $[6,13]$. Although the detection of safety risks during development provides a framework for effective mitigation, the full range of long-term adverse effects of CAR T-cell therapies remain undefined at the time of regulatory approval [14]. The FDA has provided gene therapy guidelines for industry on long-term follow-up [15]. Currently, the approved CAR T-cell therapies are only available in the USA through a risk evaluation and mitigation strategy drug safety program $[15,16]$, which restricts the distribution of these drugs to select treatment centers required to have special certification. Staff must be trained to recognize and manage defined adverse events. Agents such as tocilizumab must be available for immediate administration in the case of cytokine release syndrome.

\subsection{Advancement in Cardiac Safety}

Drug-induced cardiovascular toxicities cannot always be entirely characterized during clinical development, and an additional post-approval assessment may be required. Cardiovascular safety studies have been performed across a variety of therapeutic areas, e.g., arthritis, coronary artery disease, diabetes, obesity, and pulmonary disease. The Cardiac Safety Research Consortium, which supports research by engaging stakeholders from the pharmaceutical industry, academia, and government to collaborate and share data and expertise, is a public private partnership that was formed in 2016 [17]. This consortium acts as a think tank and shares work with electrocardiogram data, as well as other areas of cardiac safety evaluation from the preclinical, through to the post-marketing setting.

A wide range of new cardiac biomarkers are constantly being developed and evaluated to further drive efficiencies in clinical trials and drug safety evaluations with biomarkers often being interpreted as surrogates for objective outcomes. For example, while most available data pertaining to cardiotoxicity in cancer therapy come from anthracyclinebased therapies, the long-term effects of new treatments, e.g., immune therapy remain mostly unknown. Furthermore, cancer is an independent risk factor with direct effects on the cardiovascular system. Both cardiac troponin and B-type natriuretic peptide have been shown to detect subclinical cardiotoxicity during cancer treatment. Monitoring these cardio-specific biomarkers should be strongly considered and could predict which patients are at risk of developing cardiotoxicities even before the start of therapy [17].

\subsection{Cardiovascular Outcome Trials}

Regulators have often mandated specific post-approval requirements for evaluating the long-term cardiovascular safety of newly approved medications. This has been most evident for novel therapies aimed at treating type 2 diabetes. In 2007, controversy about the cardiovascular safety of the medication rosiglitazone led the FDA to establish new guidance for evaluating the long-term cardiovascular safety of such therapies, which stated that developers should demonstrate that new antidiabetic drugs and biologics would not result in an unacceptable increase in cardiovascular risk [18]. As a result, every novel antidiabetic agent approved since 2008 has undergone post-marketing cardiovascular outcome trials (CVOTs). Opinions on the overall effectiveness of these CVOTs in better characterizing the long-term cardiovascular benefit-risk profile, however, highlighted limitations of the approach [19, 20]. In 2018, the Endocrinologic and Metabolic Drugs Advisory Committee reviewed the Agency's 2008 guidelines and narrowly supported continuation of CVOTs to exclude unacceptable increases in cardiovascular risk for all new glucose-lowering therapies, but with general agreement that modification of the 2008 guidance was needed [21].

In March 2020, the FDA released new draft guidance based upon more than a decade of data from CVOTs that indicated no increased risk of ischemic cardiovascular events with anti-diabetic therapies. The updated guidance no longer includes a recommendation that companies conduct CVOTs to demonstrate cardiovascular safety of type 2 diabetes medications and instead proposes an updated approach to evaluating the broader safety profile of new drugs and biologics to improve glycemic control [22]. 
It is incontrovertible that the CVOTs provide valuable long-term cardiac safety information that will help diabetologists, cardiologists, endocrinologists, nephrologists, and general practitioners weigh the benefits and risks of treatment with antidiabetic medications. The pharmaceutical industry and its PV function played a critical role in collecting and providing the essential data that led to these advancements [23].

\subsection{Real-World Evidence for Pharmacovigilance}

Real-world evidence (RWE) and real-world data (RWD) have become key components of clinical development and healthcare decisions. The 21st Century Cures Act, passed in 2016, places an additional focus on the use of these types of data to support regulatory decision making, including approval of new indications for approved drugs. A 2017 White Paper produced by the Duke Margolis Center for Health Policy describes RWD as data relating to patient health status and/or the delivery of healthcare routinely collected from a variety of sources, e.g., electronic health record, payer claims data, registries, and mobile apps and digital technologies; while RWE is defined as evidence derived from RWD through the application of research methods. For regulatory applications, RWE can further be defined as clinical evidence regarding the use and potential benefits or risks of a medical product derived from analysis of RWD [24].

Real-world evidence is broader than simple observational data and retrospective analysis; it involves data validation and standardization along with thoughtful study designs to assess the effects of the treatments on the outcomes of interest, and an understanding of the context in which the treatments are used [24]. In the Second Annual Duke-Margolis Conference on Real-World Data and Evidence in 2018, use of RWD was further explored, including in oncology and rare diseases where ethical considerations may make randomized controlled trials difficult to conduct [25]. An additional workshop and White Paper further explored the role of RWE, as part of a total evidence package. Real-world evidence can help evaluate marketed product effectiveness along with the benefit-risk profile and possibly contribute to a labeling change [26].

The contributions of RWD and RWE to clinical trials continue to evolve through partnerships that support medical and scientific excellence. The Clinical Trials Transformation Initiative, started as a public private partnership between Duke University and the FDA, currently comprises more than 80 member organizations representing academia, clinical investigators, government and regulatory agencies, industry, institutional review boards, patient advocacy groups, and other stakeholders. Their multi-stakeholder project teams use various research methods to gain an objective understanding of evidence and promote the adoption of recommendations to improve the design of clinical trials [27]. The Multi-Regional Clinical Trials Center at Brigham and Women's Hospital and Harvard Medical School has collaborated with Optum Labs to determine the limitations of RWE from various data sources (e.g., claims, electronic health records) and whether observational studies using RWE can replicate randomized controlled trials submitted for regulatory decision making and help our understanding of the effectiveness for on-label indications in approved populations [28].

Real-world evidence has implications for PV, as data mining from RWD can provide valuable information regarding adverse effects and drug interactions. The COVID-19 outbreak has augmented the importance of the integration and the interpretation of this type of data in benefit-risk assessments of the many therapies explored, such as azithromycin, hydroxychloroquine, and chloroquine [29]. Additionally, RWD from patients with COVID-19 have supported the risk assessment for hypertensive patients receiving angiotensin system modulation drugs [30]. Pharmacovigilance must now balance the risk from treatment delay vs harm from COVID19, minimize negative effects of social distancing during the delivery of care, and appropriately allocate limited healthcare resources.

\section{PILLAR II: Operational and Compliance Excellence}

The examples below indicate why optimal PV function requires an all-time inspection-readiness PV system with dedicated and highly trained medical, scientific, and operationally technical and tactical professionals, who are proactive to ensure that commitments to various regulations worldwide are met.

\subsection{Example of the Structured Benefit-Risk Assessments Across the Therapeutic Product Lifecycle}

Benefit-risk assessment involves a set of activities and methodologies to determine whether there are new or changed risks associated with active substances or medicinal products based on various sources of data, including risk minimization programs, which vary across regulatory agencies [31-33]. Comparing elements of benefit-risk frameworks reveals the variability in how sponsors and marketing authorization holders provide these assessments. Inconsistencies could result in distinctive interactions with regulatory authorities and the final implementation of non-harmonized risk minimization programs in different territories for the same products. For example, the comparison of prasugrel 
and certolizumab pegol on US and European Union risk minimization program legislation showed a difference in risk minimization timeline update requirements and to whom the updates are communicated [34]. Most recently, with the emergence of the COVID-19 pandemic, there is an example of the use of the Benefit-Risk Action Team framework to assess the overall benefit-risk profile of the use of remdesivir as a treatment for COVID-19 compared with standard of care, placebo, or other treatments [35].

The need for global harmonization of benefit-risk legislation continues to evolve [36], including the 2016 International Council for Harmonisation revision of the content of Common Technical Document ICH M4E(R2) Section 2.5.6 "Benefits and Risks Conclusions" [37]. The revision includes division into sections on therapeutic context, benefit, risk, and the benefit-risk assessment, which must now succinctly and critically communicate the benefits and risks of the product. The focus should be on key benefits and risks while describing and interpreting the data. Regulators are recognizing that benefit-risk assessment is a rapidly evolving field and are open to flexibility with different approaches. While PV primarily has a focus on safety risks, it considers efficacy in the assessment of the benefit-risk profile of products.

\subsection{Example of the "Safety Assessment for Investigational New Drug Safety Reporting" Draft Guidance for Industry from FDA}

The increasing volumes of reported adverse events can be overwhelming for both the industry as the reporter and the FDA as the receiver. Solutions must address the tremendous challenge of balancing the timely expedited regulatory reporting of meaningful adverse events, while ensuring prompt detection and management of safety-related medical matters. The agency had issued the Safety Assessment for Investigational New Drug (IND) Safety Reporting Draft Guidance for Industry in October 2015, a guidance to sponsors on developing a systematic approach for investigational new drug application safety reporting for human drugs and biological products $[32,38]$. The guidance includes recommendations on how to identify and evaluate important safety information; the establishment of a Safety Assessment Committee; the aggregate analysis for comparison of adverse event rates across treatment groups; the planned unblinding of safety data; reporting thresholds for IND safety reporting; and the development of a safety surveillance plan. An FDAsponsored public workshop was held in 2018 to engage in discussions and share feedback about this draft guidance. Multiple efforts have been made to ensure that companies are ready for the implementation of that guidance.
Approaches can vary and harmonization needs to be addressed toward achieving a meaningful regulatory reporting of safety data. In 2020, TransCelerate, a non-profit entity composed of many global drug companies, published their assessment on how sponsors can address the principles of the 2015 draft guidance [39].

\section{PILLAR III: Knowledge Sharing and Developing Experts in the Field}

Healthcare professionals with training and experience in clinical medicine are key contributors within PV functions in regulatory agencies, academia, and the pharmaceutical industry. Their medical and scientific expertise is essential for adverse events to be accurately characterized and assessed within the context of a product's benefits and risks, and their knowledge of patient care and healthcare delivery is invaluable for developing effective risk mitigation strategies. It is therefore essential that the knowledge of professionals practicing $\mathrm{PV}$ keeps pace.

As important as being effective, approved medications should have an advantageous benefit-risk assessment in the patient populations they are intended to treat. Consequently, it is critical that medical, scientific, and other professionals are highly trained in the specialized area of PV (i.e., drug safety) and the associated various regulations that control both the development and post-marketing approval of medications.

Both degree (Diploma and Masters of Science, see Table 1) and non-degree (online course or private certification, see Table 2) training programs are available for students and healthcare professionals in the USA and are sponsored by academia and professional organizations in the USA and Canada. Non-degree training comes with multiple approaches such as stand-alone courses and workshops, professional conferences, and other venue training. The benefits of such programs ensure that the expertise of $\mathrm{PV}$ professionals remains at a high level and is current. They also help to refresh the current personnel and, in the longer term, support and encourage the future influx to the field by physicians, nurses, pharmacists, and regulators. Thus, PV professionals rely on internal training and especially external programs to supplement their learning and keep up with rapidly changing demands. Many of these are supported by the pharmaceutical companies.

Degree training comes by integrating PV concepts into existing continuing education and is available for PV professionals who have a broad healthcare or pharmaceuticals background. For even the formally and well-trained PV expert, there is a need to continuously expand their 
knowledge in PV to continuously adapt to a rapidly changing scientific and regulatory landscape [40].

\subsection{Partnership Opportunities for Pharmacovigilance Education and Training are Being Offered to Students Seeking Education in Pharmacovigilance}

Traditional curricula in medical, public health, and pharmacy schools do not emphasize drug safety and PV. This deficiency not only impacts the understanding of reporting obligations, but also diminishes the potential talent pipeline and the importance of patient safety, in addition to efficacy, as a critical aspect of drug development.

While formal PV training programs exist, most PV specialists gain their expertise through at least a baseline understanding of statistical methods and analytical problem solving combined with a broad knowledge of pharmacology and clinical medicine. Often this is followed by a hierarchy of training experiences that involve increasing exposure and responsibilities in an apprenticeship environment. The pharmaceutical industry has already committed to attract and develop potential talents through various pathways by investing in future generations of PV professionals and providing

Table 1 Academic and proprietary degree training programs in pharmacovigilance (PV) in USA and Canada

\begin{tabular}{|c|c|}
\hline Program & Program features \\
\hline $\begin{array}{l}\text { Academy of Applied Pharmaceutical Sciences, Toronto, ON, } \\
\text { Canada } \\
\text { Post-Graduate Diploma: Clinical Research, Drug Safety and PV } \\
\text { https://www.aaps.ca/diploma/clinical-research-drug-safety-and-pharm } \\
\text { acovigilance-diploma-program }\end{array}$ & $\begin{array}{l}\text { Introduction to PV and PE studies, PV regulations and PV practices, } \\
\text { ADR reporting, clinical study and safety reporting activities, post- } \\
\text { marketing compliance for safety monitoring, GCP and GVP inspec- } \\
\text { tions and audits }\end{array}$ \\
\hline $\begin{array}{l}\text { Durham Technical Community College, Durham, NC, USA } \\
\text { A.S. in Medical Product Safety and PV } \\
\text { https://www.durhamtech.edu/courses?field_class_format=All\&field__ } \\
\text { location=All\&name=\&field_title=Medical+Product+Safety+ }\end{array}$ & $\begin{array}{l}\text { Courses on drug safety, safety regulations, safety reporting, safety sys- } \\
\text { tems and processes, signal detection and risk assessment, fieldwork }\end{array}$ \\
\hline $\begin{array}{l}\text { Massachusetts College of Policy and Health Sciences, Boston, MA, } \\
\text { USA } \\
\text { PharmD fellowships in PV } \\
\text { https://www.mcphs.edu/academics/postgraduate-opportunities/bioph } \\
\text { armaceutical-fellowships/drug-safety }\end{array}$ & $\begin{array}{l}\text { The primary purpose of these fellowships is to evaluate the safety } \\
\text { profile of products throughout the development, approval, and post- } \\
\text { marketing process to enable healthcare professionals and patients to } \\
\text { make informed decisions. PharmDs will participate in implementing } \\
\text { and evaluating risk management strategies and conduct post-market- } \\
\text { ing safety surveillance } \\
\text { Medical safety and risk management (Agios) } \\
\text { Global drug safety (Alexion) } \\
\text { Global safety (Biogen) } \\
\text { Global PV (Sanofi Genzyme) } \\
\text { Global PV [2 years] (Takeda) }\end{array}$ \\
\hline $\begin{array}{l}\text { Rutgers University, Newark, NJ, USA } \\
\text { M.Sc. in Clinical Trials Sciences, w/ concentration in Drug Safety and } \\
\text { PV } \\
\text { Online Certificate in Drug Safety and PV } \\
\text { https://shp.rutgers.edu/health-informatics/master-of-science-clinical- } \\
\text { trial-sciences/ } \\
\text { PharmD fellowships in PV } \\
\text { https://pharmafellows.rutgers.edu/companies.php?id=bayerhealthcare }\end{array}$ & $\begin{array}{l}\text { Courses on regulatory requirements: clinical trials, risk management } \\
\text { tools, analyzing clinical data for AEs [14], AE reporting and post- } \\
\text { marketing activities, principles of PV and drug safety reporting } \\
\text { Fellowship programs with partner companies: Bayer-PV, risk manage- } \\
\text { ment fellowship; Johnson \& Johnson, consumer medical safety; } \\
\text { Merck, clinical safety and risk management; Roche Group, drug } \\
\text { safety and risk management; Sanofi, global PV }\end{array}$ \\
\hline $\begin{array}{l}\text { Sollers College, Edison, NJ, USA } \\
\text { M.Sc. in PV and Drug Safety } \\
\text { https://www.sollers.edu/life-science/ }\end{array}$ & $\begin{array}{l}\text { The Master of Science in Drug Safety and PV Program caters to the } \\
\text { needs of this ever-growing and highly regulated industry by offering } \\
\text { a curriculum that is highly competent and in alignment with the real- } \\
\text { time requirements from the pharmaceutical industry's point of view }\end{array}$ \\
\hline $\begin{array}{l}\text { Temple University, Philadelphia, PA, USA } \\
\text { M.Sc. in Global Clinical and PV Regulations } \\
\text { [Pre-Masters Certificate Program in Global PV] } \\
\text { https://pharmacy.temple.edu/academics/master-science-global-clinical- } \\
\text { and-pharmacovigilance-regulations-gcpr }\end{array}$ & $\begin{array}{l}\text { The MS in Global Clinical and PV Regulations focuses on both disci- } \\
\text { plines of clinical trials and PV, enabling PharmD graduates to pursue } \\
\text { positions as clinical trial project managers, research administrators, } \\
\text { safety managers, and safety directors in the global marketplace. } \\
\text { Courses on good PV operations, pharmaco-epidemiology, regulatory } \\
\text { and legal basis of PV, risk management and safety signaling, and } \\
\text { post-marketing safety surveillance }\end{array}$ \\
\hline
\end{tabular}

$A D R$ adverse drug reaction, $A E$ adverse event, $G C P$ Good Clinical Practice, GVP Good Pharmacovigilance Practices, $P E$ pharmacoepidemiological Research process: online search conducted for academic and proprietary degree training programs in PV in USA and Canada documented and confirmed the existence of the programs throughout September to October 2020 
Table 2 Academic and proprietary non-degree training programs in pharmacovigilance (PV) in USA and Canada

Program
Academy of Applied Pharmaceutical Sciences, Toronto, ON,
Canada
Certificate in Drug Safety and PV
https://www.aaps.ca/diploma/clinical-research-drug-safety-and-pharm
acovigilance-diploma-program/introduction-to-pharmacovigilance-
activities-and-pharmacoepidemiological-studies-online

Barnett International, Needham, MA, USA

Online and in-person certifications

https://www.barnettinternational.com/EducationalServices_Searc

hResults.aspx?q=pharmacovigilance

\section{Biopharma Institute, Paramus, NJ, USA}

Certificate in Drug Safety

https://www.biopharmainstitute.com/search-courses?query=drug\% 20safety

Bloomberg School of Public Health, Johns Hopkins University, Baltimore, MD, USA

Online Certificate Program: Quality, Patient Safety and Outcomes

Research

https://www.jhsph.edu/courses/list/?keyword=patient+safety \&yearId= 2020

Canadian College of Healthcare and Pharmaceutics, Toronto, ON, Canada

PV Certificate

http://www.cchap.ca/program/pharmacovigilance/

Canadian Academy for Healthcare Professionals, Toronto ON, Canada

PV Certificate

http://www.cahp-edu.ca/workshops/pharmacovigilance/

Drug Information Association

Online or as short courses offered in US cities

Certificate in Clinical Safety and PV

https://www.diaglobal.org/en/course-listing/certificate-program/safetyand-pharmacovigilance

PV: All About Patient Safety

Online training programs

https://allaboutpharmacovigilance.org/courses/

Royal Canadian College of Distance Education, Mississauga, ON, Canada

Certificate online training program

http://rccdistance-education.com/event/pharmacovigilance-trainingcourse/

RxCourse $^{\mathrm{TM}}$ Mississauga, ON, Canada

Online Drug Safety and PV Certificate

https://www.innovigilance.com/

SJ Pharma Consulting, LLC, Mendham, NJ, USA

Online and in-person certifications

http://sjpharmaco.com/pv-training-material

University of Southern California, Los Angeles, CA, USA

Certificate in Patient and Product Safety, School of Pharmacy https:// regulatory.usc.edu/resources/events/understanding-pharmacovigilan ce-operations/
Program features

Introduction to $\mathrm{PV}$ and $\mathrm{PE}$ studies, $\mathrm{PV}$ regulations and $\mathrm{PV}$ practices, ADR reporting, clinical study and safety reporting activities, postmarketing compliance for safety monitoring, GCP and GVP inspections and audits

Drug safety and PV: effective drug safety

Basics of post-marketing PV and the beginner PV audit

Advanced post-marketing PV auditing

Quality risk management in clinical trials and PV

Case narrative writing for reporting adverse events

EMA and FDA inspections: key differences and similarities

Introduction to drug safety and PV, urgent safety restrictions, risk management planning for medicinal products, signal detection, and management in PV

This course is not a PV program, but offers several courses on medication errors and human factors

This 2-day program helps you to better understand the fundamental principles of PV including major regulatory authority's laws, regulations, and guidelines, including Health Canada guidance documents

This 2-day program gives you a better understanding of the fundamental principles of PV. It will cover major regulatory authorities' laws, regulations, and guidelines including Health Canada guidance documents

Drug Information Association Safety and PV Certificate Program is a competency-based program that outlines the functional knowledge and skills needed to work in safety and PV and comply with US and EU regulations

Several PV courses and includes drug safety forum, PV guidance materials, articles, and books

This PV training course was designed to meet the needs of those involved in any aspect of PV to help you to comply with Canadian and US requirements

Learning based on the FDA, EMA, PMDA, Health Canada, and ICH guidelines and regulation on GVP to leverage compliance

A course that covers all the essential components of drug safety and PV

Drug safety and PV are undergoing dramatic change from simple adverse event reporting to comprehensive signal and benefit-risk management processes. In this course, attendees will be introduced to the core aspects of best practices by industry experts

$A D R$ adverse drug reaction, EMA European Medicines Agency, EU European Union, FDA US Food and Drug Administration, GCP Good Clinical Practice, GVP Good Pharmacovigilance Practices, ICH International Council for Harmonisation of Technical Requirements for Pharmaceuticals for Human Use, PE Pharmacoepidemiological, PMDA Pharmaceutical and Medical Devices Agency

Research process: online search conducted for academic and proprietary degree training programs in PV in USA and Canada documented and confirmed the existence of the programs throughout September to October 2020 
opportunities for them to learn more about the pharmaceutical industry $[41,42]$.

\subsection{Internship Programs}

Internship programs can be offered to undergraduate college students to provide an opportunity to learn about PV. During a summer internship, a student might be assigned a short-term, e.g., 12-week project that provides an opportunity to work within a PV department and interact with PV experts and key stakeholders. The student intern benefits from mentorship and provides valuable contributions, including selecting a project of interest and presenting his/ her perspectives at the end of the program. Applications and opportunities for PV internship programs are found on relevant pharmaceutical company websites as applicable and by searching for the phrase "pharmacovigilance internships" using any internet search engine. Rotation programs have been established between schools of pharmacy and the pharmaceutical industry offering for the pharmacy student to be fully immersed in a PV department as part of his/her educational curriculum [43].

\subsection{Fellowship Programs}

Fellowship programs represent a longer term (e.g., 2 years) commitment, i.e., usually a post-doctoral program targeted toward recent Doctor of Pharmacy graduates and coordinated by both the pharmaceutical company and a sponsoring university. Through offering real-world, hands-on, and in-depth specialized training, the PV fellowship provides healthcare professionals an opportunity within a corporation to develop skills, knowledge, and experience to further explore a potential career as a PV expert. Fellowship opportunities have been increasingly offered by pharmaceutical companies to graduate students.

These programs have been established between the pharmaceutical industry and academia, where, for example, recent graduates from a school of pharmacy or school of public health may apply for fellowship positions in the pharmaceutical industry. The focus of a fellowship curriculum may vary somewhat, but the primary objectives for these positions are to educate the fellow on how to evaluate the safety profile of products throughout the life cycle of development, approval, and post-marketing setting, offering in some instances to contribute with implementing and evaluating risk management strategies and with conducting postauthorization safety studies. After the completion of their program, fellows could have the opportunity to apply for available PV subject matter expert positions [43].

\section{Summary and Conclusions}

A comprehensive and compliant PV system of regulated processes and tools worldwide is mandated and critical to ensure patient safety through a set of multiple and complex PV activities. The proposed approach of a three-pillar model for PV is intended to help the PV professional to establish functions that will foster robust scientific and medical excellence, implement operational and compliant PV capabilities, and foster the commitment to the hiring, retention, and continuous development of strong PV experts. In the spirit of strengthening a community of PV experts, the sharing of experiences and the continued collaboration and education among PV colleagues will ensure that best practices are implemented.

We describe a model of three pillars as the tenets that support an efficient and successful PV framework, i.e., (1) medical and scientific excellence, (2) operational and compliance excellence, and (3) knowledge sharing and experts development in the field. The authors elaborate on these concepts and demonstrate how this model helps the PV expert organize the discipline. Using examples of cutting-edge science in clinical drug development and new technologies and methods for assessing safety, the authors shed light on how these essential components come together from the US experience with universal implications. In addition, the authors emphasize the importance of promoting formal training and continued education to ensure PV excellence now and in the future.

\section{Declarations}

Funding No funding was received for the preparation of this article.

Conflict of interest Veronique F. Kugener is employed and holds stocks in Takeda Pharmaceuticals International Co. She has no potential conflict of interest related to the content of this article. Eric S. Freedland is employed by Takeda Pharmaceuticals International Co. and has no potential conflict of interest related to the content of this article. Kenneth I. Maynard is employed by Takeda Pharmaceuticals International Co., is a member of the National Advisory Neurological Disorders and Stroke (NANDSC) Council (designated as Special [US] Government Employee), and is a founder/CEO of Career and Corporate Coaching, LLC. He holds stocks and options with AAL, AAPL, ALGN, ALT, AMAT, BIG, BTSC, FAS, FNMA, FSLR, INO, NFLX, NIO, OLED, PDD, PTON, SSO, TSLA, XME, UAL, WFH, ZM, and SAN. Kenneth I. Maynard has no potential conflict of interest related to the content of this article. Omar Aimer is employed by Brunel Canada and has no potential conflict of interest related to the content of this article. Peggy S. Webster is employed by GlaxoSmithKline and holds stocks and options in GlaxoSmithKline. She has no potential conflict of interest related to the content of this article. Maribel Salas is employed by Daiichi Sankyo, Inc. and CCEB/CPeRT, Perelman School of Medicine, University of Pennsylvania and holds stock and options in Daiichi Sankyo, Inc. Maribel Salas has no potential conflict of interest related to the content of this article. Maxine Gossell-Williams 
is employed by the Section of Pharmacology and Pharmacy, Faculty of Medical Sciences Teaching and Research Complex, University of The West Indies and has no potential conflict of interest related to the content of this article.

Ethics approval Not applicable.

Consent to participate Not applicable.

Consent for publication Not applicable.

Availability of data and material Not applicable.

Code availability Not applicable.

Author contributions All authors contributed to, edited, and approved the final manuscript.

\section{References}

1. Dunbar CE, High KA, Joung JK, Kohn DB, Ozawa K, Sadelain M. Gene therapy comes of age. Science. 2018;359(6372):eaan4672. https://doi.org/10.1126/science.aan4672.

2. Cavero I, Seimetz D, Koziel D, Zimmermann W-H, Holzgrefe HH. 19th Annual meeting of the safety pharmacology society: regulatory and safety perspectives for advanced therapy medicinal products (cellular and gene therapy products). Expert Opin Drug Saf. 2020;19(5):553-8. https://doi.org/10.1080/14740338.2020. 1741546.

3. Richardson A, Apaydin E, Baxi S, Vockley J, Akinniranye O, Ross $\mathrm{R}$, et al. Landscape review and evidence map of gene therapy, part II: chimeric antigen receptor-T cell (CAR-T), autologous cell, antisense, RNA interference (RNAi), zinc finger nuclease (ZFN), genetically modified oncolytic herpes virus. 2019. https://www. pcori.org/sites/default/files/PCORI-Emerging-Technologies-Thera peutics-ReportLandscape-Review-Evidence-Map-Gene-TherapyPart-II.pdf. Accessed 2 Oct 2020.

4. Anguela XM, High KA. Entering the modern era of gene therapy. Annu Rev Med. 2019;70:273-88. https://doi.org/10.1146/annur ev-med-012017-043332.

5. Darrow JJ, Avorn J, Kesselheim AS. FDA approval and regulation of pharmaceuticals, 1983-2018. J Am Med Assoc. 2020;323(2):164-76. https://doi.org/10.1001/jama.2019.20288.

6. O'Leary MC, Lu X, Huang Y, Lin X, Mahmood I, Przepiorka D, et al. FDA approval summary: tisagenlecleucel for treatment of patients with relapsed or refractory B-cell precursor acute lymphoblastic leukemia. Clin Cancer Res. 2019;25(4):1142-6. https:// doi.org/10.1158/1078-0432.CCR-18-2035.

7. Day RO, Williams KM. Open-label extension studies. Drug Saf. 2007;30(2):93-105. https://doi.org/10.2165/00002018-20073 0020-00001.

8. Cho MK. Open-label extension studies: are they really research? Am J Bioethics. 2014;14(4):60-1. https://doi.org/10.1080/15265 161.2014.889958.

9. Halford Z, Anderson MK, Bennett LL. Axicabtagene ciloleucel: clinical data for the use of CAR T-cell therapy in relapsed and refractory large B-cell lymphoma. Ann Pharmacother. 2020;55(3):390-405. https://doi.org/10.1177/1060028020944233.

10. Gerson JN, Barta SK. Mantle cell lymphoma and hematopoietic cell transplantation in the era of cellular therapy. J Clin Haematol. 2020;1(2):59-65. https://doi.org/10.33696/haematology.1.009.

11. Gross G, Waks T, Eshhar Z. Expression of immunoglobulin-T-cell receptor chimeric molecules as functional receptors with antibody-type specificity. Proc Natl Acad Sci USA. 1989;86(24):10024-8. https://doi.org/10.1073/pnas.86.24.10024.

12. Locke FL, Ghobadi A, Jacobson CA, Miklos DB, Lekakis LJ, Oluwole OO, et al. Long-term safety and activity of axicabtagene ciloleucel in refractory large B-cell lymphoma (ZUMA1): a single-arm, multicentre, phase 1-2 trial. Lancet Oncol. 2019;20(1):31-42. https://doi.org/10.1016/S1470-2045(18) 30864-7.

13. Riedell PA, Bishop MR. Safety and efficacy of axicabtagene ciloleucel in refractory large B-cell lymphomas. Ther Adv Hematol. 2020;11:1-12. https://doi.org/10.1177/2040620720902899.

14. Borini P, Guimarães RC, Borini SB. Possible hepatotoxicity of chronic marijuana usage. Sao Paulo Med J. 2004;122(3):110-6. https://doi.org/10.1590/S1516-31802004000300007.

15. US FDA. Long term follow-up after administration of human gene therapy products: guidance for industry. 2020. https://www.fda. gov/media/113768/download. Accessed 1 Oct 2020.

16. Bouchkouj N, Kasamon YL, de Claro RA, George B, Lin X, Lee $\mathrm{S}$, et al. FDA approval summary: axicabtagene ciloleucel for relapsed or refractory large B-cell lymphoma. Clin Cancer Res. 2019;25(6):1702-8. https://doi.org/10.1158/1078-0432. CCR-18-2743.

17. Bracun V, Aboumsallem JP, van der Meer P, de Boer RA. Cardiac biomarkers in patients with cancer: considerations, clinical implications, and future avenues. Curr Oncol Rep. 2020;22:67. https:// doi.org/10.1007/s11912-020-00930-x.

18. US FDA. Use of real-world evidence to support regulatory decision-making for medical devices, guidance for industry and Food and Drug Administration staff 2017. 2017. https://www.fda.gov/ media/99447/download. Accessed 1 Oct 2020.

19. Regier EE, Venkat MV, Close KL. More than 7 years of hindsight: revisiting the FDA's 2008 guidance on cardiovascular outcomes trials for type 2 diabetes medications. Clin Diabetes. 2016;34(4):173-80. https://doi.org/10.2337/cd16-0005.

20. Sharma A, Pagidipati NJ, Califf RM, McGuire DK, Green JB, Demets D, et al. Impact of regulatory guidance on evaluating cardiovascular risk of new glucose-lowering therapies to treat type 2 diabetes mellitus: lessons learned and future directions. Circulation. 2020;141(10):843-62. https://doi.org/10.1161/CIRCU LATIONAHA.119.041022.

21. Mullard A. FDA reconsiders cardiovascular outcomes trials for diabetes drugs, 10 years on. Nat Rev Drug Discov. 2018;17(12):850-1. https://doi.org/10.1038/nrd.2018.206.

22. US FDA. Type 2 diabetes mellitus: evaluating the safety of new drugs for improving glycemic control guidance for industry. 2020. https://www.fda.gov/media/135936/download. Accessed 18 Oct 2020.

23. Sportiello L, Rafaniello C, Scavone C, Vitale C, Rossi F, Capuano A. The importance of pharmacovigilance for the drug safety: focus on cardiovascular profile of incretin-based therapy. Int J Cardiol. 2016;202:731-5. https://doi.org/10.1016/j.ijcard.2015.10.002.

24. Berger M, Daniel G, Frank K, Hernandez A, McClellan M, Okun S. A framework for regulatory use of real world evidence. White paper prepared by the Duke Margolis Center for Health Policy. 2017. https://healthpolicy.duke.edu/sites/default/files/2020-08/ rwe_white_paper_2017.09.06.pdf. Accessed 1 Oct 2020.

25. Daniel G, Silcox C, Bryan J, McClellan M, Romine M, Frank K. Characterizing RWD quality and relevancy for regulatory purposes. 2018. https://healthpolicy.duke.edu/sites/default/files/ 202003/characterizing_rwd.pdf. Accessed 1 Oct 2020.

26. McClellan M, Daniel G, Sherman R. Adding real-world evidence to a totality of evidence approach for evaluating marketed product effectiveness. Duke Margolis Center for Health Policy. 2019. https://healthpolicy.duke.edu/sites/default/files/2020-08/Totality\% 20of\%20Evidence\%20Approach.pdf. Accessed 1 Oct 2020. 
27. Clinical Trials Transformation Initiative. 2020. https://www.ctticlinicaltrials.org/. Accessed 1 Oct 2020.

28. Multi-Regional Clinical Trials Center. Real world evidence. 2020. https://mrctcenter.org/blog/projects/realworld-evidence/. Accessed 1 Oct 2020.

29. Sultana J, Cutroneo PM, Crisafulli S, Puglisi G, Caramori G, Trifirò G. Azithromycin in COVID-19 patients: pharmacological mechanism, clinical evidence and prescribing guidelines. Drug Saf. 2020;43(8):691-8. https://doi.org/10.1007/ s40264-020-00976-7.

30. Trifirò G, Crisafulli S, Andò G, Racagni G, Drago F. Should patients receiving ACE inhibitors or angiotensin receptor blockers be switched to other antihypertensive drugs to prevent or improve prognosis of novel coronavirus disease 2019 (COVID-19)? Drug Saf. 2020;43:507-9. https://doi.org/10.1007/s40264-020-00935-2.

31. Mullin TM, Barton JL. US Prescription Drug User Fee Act (PDUFA): an introduction for the pharmaceutical physician. Pharm Med. 2017;31(1):7-12. https://doi.org/10.1007/ s40290-016-0170-6.

32. Banerjee AK, Zomerdijk IM, Wooder S, Ingate S, Mayall SJ. Postapproval evaluation of effectiveness of risk minimisation: methods, challenges and interpretation. Drug Saf. 2014;37(1):33-42. https://doi.org/10.1007/s40264-013-0126-7.

33. Kay J, Feagan BG, Guirguis MS, Keystone EC, Klein AV, Lubiniecki AS, et al. Health Canada/BIOTECanada Summit on regulatory and clinical topics related to subsequent entry biologics (biosimilars), Ottawa, Canada, 14 May 2012. Biologicals. 2012;40(6):517-27. https://doi.org/10.1016/j.biologicals.2012. 09.010 .

34. Lis Y, Roberts MH, Kamble S, Guo JJ, Raisch DW. Comparisons of Food and Drug Administration and European Medicines Agency risk management implementation for recent pharmaceutical approvals: report of the International Society for Pharmacoeconomics and Outcomes Research Risk Benefit Management Working Group. Value Health. 2012;15(8):1108-18. https://doi. org/10.1016/j.jval.2012.06.019.

35. Davies M, Osborne V, Lane S, Roy D, Dhanda S, Evans A, et al. Remdesivir in treatment of COVID-19: a systematic benefit-risk assessment. Drug Saf. 2020;43:645-56. https://doi.org/10.1007/ s40264-020-00952-1.
36. Ball G, Kurek R, Hendrickson BA, Buchanan J, Wang WW, Duke SP, et al. Global regulatory landscape for aggregate safety assessments: recent developments and future directions. Ther Innov Regul Sci. 2020;54(2):447-61. https://doi.org/10.1007/ s43441-019-00076-4.

37. Revision of M4E guideline of enhancing the format and structure of benefit-risk information in ICH: Efficacy - M4E(R2). 2020. https://database.ich.org/sites/default/files/M4ER2Guideline.pdf. Accessed 1 Oct 2020

38. US FDA. Safety assessment for IND safety reporting guidance for industry: draft guidance. 2015. https://www.fda.gov/files/drugs/ published/Safety-Assessment-for-IND-Safety-Reporting-Guida nce-forIndustry.pdf. Accessed 18 Oct 2020.

39. TransCelerate. Industry experience and perspective on clinical trial safety reporting to the FDA. White Paper 2015. 2015. http:// transceleratebiopharmainc.com/wp-content/uploads/2020/03/ TransCelerate_INDSafety-Reporting-to-FDA_March-2020.pdf. Accessed 1 Oct 2020.

40. McCarthy D, Harrison-Woolrych M. ISoP fellowships: recognising contributions to the goals of ISoP. Drug Saf. 2020;43:297300. https://doi.org/10.1007/s40264-020-00921-8.

41. Massachusetts College of Pharmacy. Drug safety fellowships. 2021. https://www.mcphs.edu/academics/postgraduate-opportunit ies/biopharmaceutical-fellowships/drug-safety. Accessed $17 \mathrm{Feb}$ 2021.

42. Industry Pharmacists Organization. Industry fellowship catalog. 2021. https://www.industrypharmacist.org/catalog_fellowship. php. Accessed 17 Feb 2021.

43. Melillo S, Gangadharan A, Johnson H, Schleck P, Steinberg M, Alexander JG. Postdoctoral pharmacy industry fellowships: a descriptive analysis of programs and postgraduate positions. Am J Health Syst Pharm. 2012;69(1):63-8. https://doi.org/10.2146/ ajhp110104. 